\title{
Multidisciplinary challenge in the design of a MWCNTs-based polymer smart structure
}

\author{
Maurizio Arena ${ }^{1, *}$, Massimo Viscardi ${ }^{1}$, Liberata Guadagno ${ }^{2}$, Luigi Vertuccio ${ }^{2}$, and \\ Giuseppina Barra $^{2}$ \\ ${ }^{1}$ Department of Industrial Engineering - Aerospace section, University of Naples "Federico II", \\ Via Claudio, 21, Naples, 80125, Italy \\ ${ }^{2}$ Department of Industrial Engineering, University of Salerno, Via Giovanni Paolo II, 132, Fisciano, \\ Salerno, 84084, Italy
}

\begin{abstract}
Smart structures represent of course a current challenge for the application on the aircrafts. Dealing for example with morphing and variable-shape structures, the skin needs to face extremely high strains, while withstanding the operational loads in order to ensure a smooth profile to the complete system. In this context, the authors led the design and manufacturing of carbon fiber-reinforced composite panels, including different filler infusions based on multi-walled carbon nanotubes (MWCNTs) technology. The vibro-acoustic tests have been carried out on an innovative formulation for the characterization of the damping properties related to such micro-handling treatments. The percentage of nano-filler has been chosen so as to be close to the percolation threshold of the material (about $5 \mathrm{wt} \%$ ). As a result of synergic collaboration between Smart Structures Lab of University of Naples "Federico II" and University of Salerno within H2020-MASTRO (Intelligent bulk MAterials for Smart TRanspOrt industries) research project, a multi-functional composite concept has been idealized and developed. The main purpose is to develop intelligent bulk materials for the transport field based on the novel concepts like self-sensing, self-deicing, self-curing, self-healing and selfprotection methodologies to enhance consumer safety, component life-span and performance while reducing maintenance and manufacturing costs. The functionality of the developed components will be demonstrated under relevant conditions at prototype level with special attention to the aerospace structures.
\end{abstract}

*Corresponding author: maurizio.arena@unina.it 


\section{Introduction}

The aeronautical industry is moving towards the application of composite materials more and more advanced in order to fulfill the stringent airworthiness requirements. Nanotechnology offers in this perspective the possibility to introduce multifunctionality properties and greater durability in a single load bearing materials. This activity was focused on the effect of multi-walled carbon nanotubes on the damping capability in laminate carbon nanotubes/epoxy composites under a dynamic loading. The composite demonstrator was made from carbon fibers and carbon nanotubes randomly distributed into epoxy resin. The amount of carbon nanotubes dispersion was varied up to $0.5 \%$ by weight. Modal impact tests were carried out to obtain the impulsive response of specimen with dimensions of $41 \times 41 \mathrm{~mm}^{2}$.

\section{Materials and methods}

GPOSS in the form of viscous liquid was dispersed in the epoxy mixture T20BD at concentration of $5 \mathrm{wt} \%$. The dispersion process was consisting in $20 \mathrm{~min}$ ultra-sonication at $90^{\circ} \mathrm{C}$ followed by magnetic stirring at $120^{\circ} \mathrm{C}$. The Epoxy blend and DDS were mixed at $120{ }^{\circ} \mathrm{C}$, and MWCNTs were added and incorporated into the matrix by using ultrasonication for $20 \mathrm{~min}$. CFRCs were manufactured using an unusual bulk infusion technique as described in [1-6].

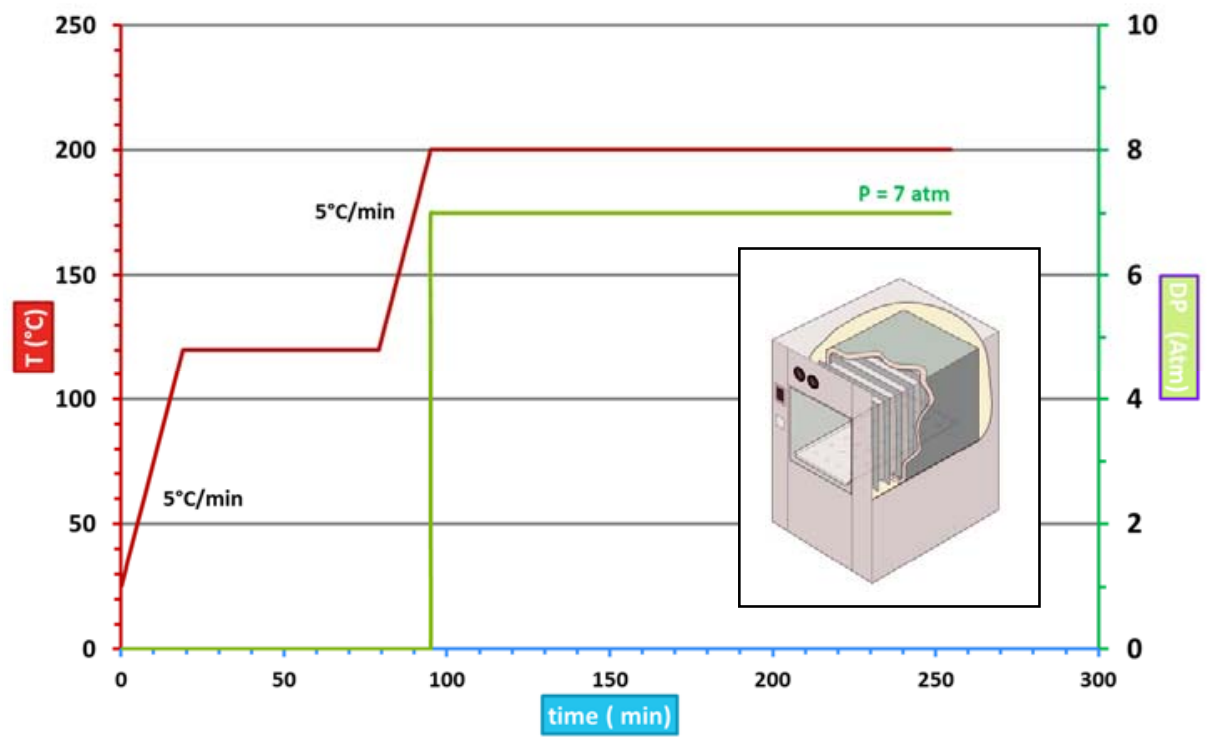

Fig. 1. Impregnation and curing cycle.

\section{Experimental results}

The vibration tests, according to the impact technique, were carried out on the manufactured sample in order to estimate the modal parameters, and in particular the damping ratio, [7-12]. The test item has been tied by means of two very soft springs at the test rig, so as to be as close to a free-free constraint condition. A PCB tri-axis accelerometer 
has been placed in a fixed point of the structure, while a PCB microphone on a tripod at about $30 \mathrm{~cm}$ from the central point of the surface. The acquisitions were performed in the range $[0 ; 200 \mathrm{~Hz}$, recording the Frequency Responses Functions (FRF) following impulsive excitations on a reference grid defined on the panel (roving hammer), Figure 4. In such a way, the reconstruction of the mode shapes has been elaborated at the end of the test. A high damping ratio (over 3\%) has been observed for the nano-filled specimen with respect to the modal shapes comprised in the observed bandwidth, Figure 2.

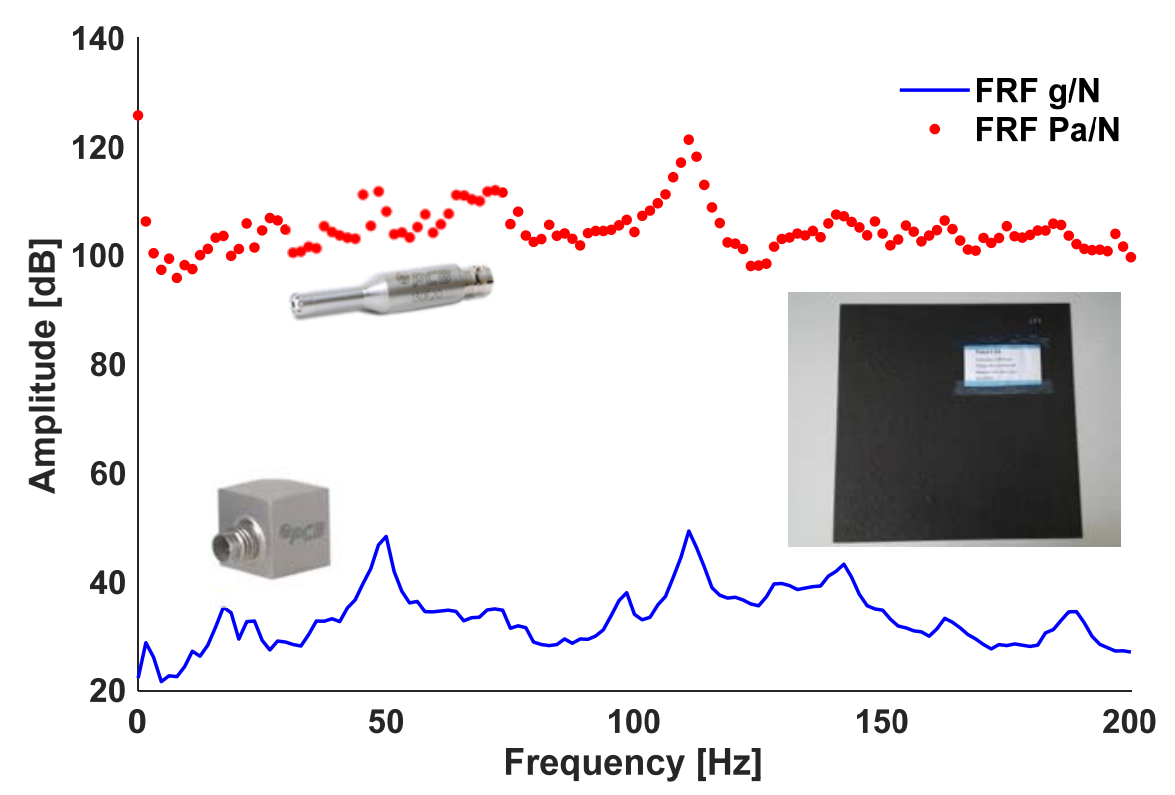

Fig. 2. Dynamic response of the structure.

\section{Main conclusions and future research}

The extensive and growing use of composite materials in aeronautical constructions, including for primary structure elements, requires more information on their behavior, not just from a structural perspective but the vibro-acoustic one too. Current research is moving toward implementing these solutions in the field of transport engineering, especially for civil aircraft. Moreover, the composite materials, unlike the metallic alloys, can include in their layup other chemical components, targeted to improve certain performance. This study investigates the dynamic behavior and the energy dissipating effect of the laminated composites-based MWCNTs. An impulsive level of the impact force was used for the estimation of the spectral response of the sample. The effect of the impact acceleration on the mechanical behavior of the composite-based MWCNT was then investigated. Starting from laboratory parameters estimated on simple components, the next step will concern the trade-off evaluations with respect different percentage of nanotubes and different electromechanical properties.

The research leading to these results has received funding from the European Union Horizon 2020 Programme under Grant Agreement n ${ }^{\circ} 760940$. 


\section{References}

1. L. Guadagno, M. Raimondo, U. Vietri, G. Barra, L. Vertuccio, R. Volponi, G. Cosentino, F. De Nicola, A. Grilli and P. Spena, AIP Conference Proceedings, 1599 (2014), Article number 461

2. G. Barra, L. Vertuccio, U. Vietri, C. Naddeo, H. Hadavinia, L. Guadagno, Materials 10(10), 1131 (2017)

3. L. Vertuccio, L. Guadagno, G. Spinelli, P. Lamberti, V. Tucci, S. Russo, Composites Part B: Engineering 107, 192-202 (2016)

4. G. Barra, L. Guadagno, B. Simonet and B. Santos, AIP Conference Proceedings, 1736 (2016), Article number 020158

5. G. Barra, F. De Nicola, B. De Vivo, L. Egiziano, L. Guadagno, P. Lamberti, M. Raimondo, G. Spinelli, V. Tucci, L. Vertuccio, U. Vietri and R. Volponi, 2014 IEEE 9th Nanotechnology Materials and Devices Conference, NMDC 2014

6. G. Barra, L. Vertuccio, C. Naddeo, M. Arena, M. Viscardi, L. Guadagno, AIP Conference Proceedings, 1981 (2018), Article number 020149

7. M. Viscardi, M. Arena, G. Barra, L. Guadagno, International Journal of Mechanics 10, 376-382 (2016)

8. M. Viscardi, M. Arena, G. Barra, L. Guadagno, International Journal of Mechanics 11, 51-57 (2017)

9. M. Viscardi, M. Arena, G. Barra, L. Vertuccio, M. Ciminello, L. Guadagno, Proc. SPIE 10599, Nondestructive Characterization and Monitoring of Advanced Materials, Aerospace, Civil Infrastructure, and Transportation XII, 105991C (2018), doi: $10.1117 / 12.2295938$

10. M. Viscardi, P. Napolitano, M. Arena, International Journal of Mathematical Models and Methods in Applied Sciences 10, 340-346 (2016)

11. M. Viscardi, M. Arena, L. Guadagno, L. Vertuccio, G. Barra, Special Issue: 6th EASN Association International Workshop, International Journal of Structural Integrity (2017)

12. M. Arena, L. Vertuccio, G. Barra, M. Viscardi, L. Guadagno, AIP Conference Proceedings, 1981 (2018), Article number 020066 